\title{
Echoes from the Past: Podcasting in the African American Studies Classroom
}

\author{
Cassandra Jones ${ }^{1}$
}

Keywords: podcasting, instructional technology, African American Studies, digital citizenship

\section{Framework}

Podcasting has been used to deliver lectures in traditional face-to-face, hybrid, and distance-learning classrooms. However, an increasing amount of research has explored the educational benefits of student-created podcasts. Jarvis and Dickie (2010) have noted that podcasting can allow access to deeper modes of learning. In addition to digital literacy skills, podcasting has been shown to promote confidence and provide greater motivation for participating in the course (Lee et al, 2008).

When implementing technology in the classroom my primary goal as an educator is to use it in service of the core content. As a result, this podcasting project firmly places African American Culture at the center at both phases of the project: learning how to use the podcasting software and creating a podcast to share with the class.

This quick hit describes the use of podcasting using Audacity, a free audio-editing software program, as implemented in an African American Culture class made up of 35 students. The ethnography podcast replaced a typical research paper with the aim to achieve this greater motivation and engage deeper modes of learning by asking students to explore their connections to the African American communities around them.

\section{Making It Work}

\section{Phase 1: Learning to Use Audacity}

Phase one of the project was a workshop in which students learned how to use Audacity to record, import, edit, and export audio files. These audio files, exported as .mp3s, were uploaded both to Blackboard and to a private iTunesU course page. In the two-day workshop, students were given a mini-podcast assignment through which they learned the skills they would need for the final project. Upon completion of the assignment, students had produced a oneminute mini-podcast in which the student introduces him- or herself, the title of the podcast, and frames the interview content making connections to course concepts. The assignment had the additional benefit of allowing me to incorporate supplementary historical resources into the class.

The workshop was held during two 50-minute course sessions. In order to give a group of 35 students as much guidance as possible, I requested the help of our campus's instructional design and assistive technology assistant, Winona Hatcher. We decided on iTunesU as an appropriate place for students to submit their finished products in order to give them the feeling

\footnotetext{
${ }^{1}$ Assistant Professor of African American studies, Department of Languages, Literature, and Composition, University of South Carolina Upstate, 800 University Way, Spartanburg, SC 29303, cjones@uscupstate.edu.
} 
Jones, C.

of having completed a professional podcast. As our campus has recently begun a "Bring Your Own Device (BYOD)" initiative, our students own laptops in greater numbers. These devices are also available from our Information Technology Help Desk to be borrowed for a 7-day period for students who do not own laptops. I asked the students to download and install Audacity onto their devices (using IT for guidance if necessary) before the workshop began, encouraging them to explore the program on their own as well.

Day one of the workshop asked students to edit an .mp3 recording from the Library of Congress's American Memory Collection of Slave Narratives. I provided a digital handout listing the goals for these two days with instructions on how to proceed. I showed students a YouTube video that outlined the Audacity skills they would need for the assignment, providing a link on the handout for reference. I then demonstrated these steps for them. Students chose a slave narrative to download and import into Audacity. After opening the .mp3 file, they edited it down to a 30 second clip that they could connect with course concepts. While students did this, Ms. Hatcher and I answered questions or dealt with technical difficulties. Students who moved swiftly through the assignment were encouraged to help students with questions around them or move on to the homework assignments.

In preparation for day two, students were required to reflect on the selection they had chosen and draw connections to course content. As homework, students composed and recorded an introduction to the podcast that welcomes the listener to the podcast, includes the student's name, the name of the interviewee, and frames what the listener will hear. Headphones and microphones are also available for students from the Information Technology Help Desk. I provided the students with an example of an introduction I had created for my own mini-podcast for reference.

Day two of the workshop built on the skills of downloading, importing, editing, and recording developed on the first day and asked students to layer each of their assembled pieces and export the files as a singular .mp3 file to be uploaded to Blackboard and our iTunesU course pages. We briefly reviewed the video, focusing on adding tracks, using the time shift tool to stagger them effectively, using the envelope tool to increase or decrease the volume of a track to more smoothly edit transitions between tracks, and exporting completed .aup files as .mp3 files. In addition, I reviewed the process of uploading the finished product to our Blackboard and iTunesU course pages. I discussed the importance of choosing copyright-free music and digital citizenship, including extending proper credit to others' creations and urged students to choose copyright-free music to serve as intro/outro music, to play behind their own speech track, or behind the interview for emotional affect.

Students downloaded and imported an .mp3 of copyright-free music to set the tone for their podcast, editing for time. Students used the envelope tool to alter the music's volume and the time shift tool to layer the music behind either their introduction and/or the recorded slave narrative. Once they had completed the mini-podcast to their satisfaction, they exported the file and uploaded it. In order to encourage students to engage each other's work, I assigned additional credit for listening and responding to the mini-podcast in a 150 -word minimum post on Blackboard. The assignment allowed me to keep African American Studies content at the center of a lesson about using technological tools. 
Jones, C.

\section{Phase 2: Creating and Sharing the Ethnographic Podcasts.}

This workshop prepared students to complete a longer podcast on their own. The semester-long assignment involved several steps before the completion of the five to seven minute ethnographic podcast. Choosing an area of African American culture to explore, students wrote a topic proposal, demonstrating their awareness of available research as well as naming specific interview subjects. Then they recorded the interview(s) with their subject(s). Next, they composed an annotated bibliography listing four to five sources. The fourth step was bring the recorded interview(s) and laptop to class for a final 50-minute workshop day. This workshop day was devoted to editing the final podcast with both the instructor and technology assistant available to help with any technical issues. As the final stage in the process, I asked students to share their podcasts with each other on Blackboard and the iTunesU course page. Students were evaluated based on their participation in the workshops, the quality of their research, the podcast's content, meeting length guidelines, and attention to digital citizenship.

\section{Future Implications}

Despite claims about millennial students as digital natives, many of my students were anxious about using this technology. They did not see podcasting as an accessible skill. A few students were familiar with audio editing from their other classes or their own interest in music production, but many were learning this skill for the first time and found themselves intimidated by the abundance of options presented by the program. In keeping with Lee, McLoughlin, and Chan's findings, as they completed the mini-podcasts, students became more confident in their use of the technology and were able to successfully complete longer format podcasts (Lee et al, 2008). While I have only anecdotal evidence to support this, the use of podcasting did seem to generate excitement about the course and thus greater motivation to participate.

With such a large group of first-time podcasters, Winona Hatcher's presence as an additional instructor on hand for the workshops was invaluable. For instructors without a technology pedagogy coordinator, perhaps requesting the presence of an IT technician would help with the inevitable technical issues that present themselves.

\section{References}

Jarvis, C., and Dickie, J. (2010). Podcasts in support of experiential field learning. Journal of Geography in Higher Education, 34(2), 173-186. doi: 10.1080/03098260903093653

Lee, M. J. W., McLoughlin, C., and Chan A. (2008) Talk the talk: Learner-generated podcasts as catalysts for knowledge creation. British Journal of Educational Technology, 39 (3), 501-521. 